\title{
Investigation of low voltage DC microgrid using sliding mode control
}

\author{
D. Sattianadan, G. R. Prudhvi Kumar, R. Sridhar, Kuthuru Vishwas Reddy, \\ Bhumireddy Sai Uday Reddy, Panga Mamatha \\ Department of Electrical and Electronics Engineering, SRM Institute of Science and Technology, India.
}

\section{Article Info \\ Article history: \\ Received Feb 20, 2020 \\ Revised Apr 26, 2020 \\ Accepted May 12, 2020}

\section{Keywords:}

Distributed energy resources

Droop control

Load sharing

LVDC microgrid

Parallel DC-DC converters

circulating currents

Sliding mode controller

\begin{abstract}
As the requirement of power increases, the use of renewable energy resources has become prominent. The power collected from these energy resources needs to be converted using AC-DC or DC-DC converters. The control of DC-DC converters is a complex task due to its non-linearity in the converter introduced by the external changes such as source voltage, cable resistance and load variations. Converters are to be designed to obtain a well stabilized output voltage and load current for variable source voltages and load changes. Droop control method is the most abundantly used technique in controlling the parallel converters. The major limitations of the conventional droop control technique are circulating current issues and improper load sharing. The proposed work is to resolve these issues by integrating Sliding Mode Controller (SMC) with the converter in order to enhance the performance of DC microgrid. The entire control system was designed by taking the output voltage error as the control variables. Similarly, droop control with PI and PID were also performed and all these techniques were simulated and compared using MATLAB/Simulink. The experimental results show that the proposed sliding mode controller technique provides good overall performance and is suitable against variable voltage and load changes.
\end{abstract}

This is an open access article under the CC BY-SA license.

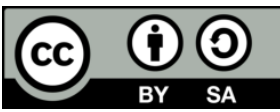

Corresponding Author:

D. Sattianadan,

Department of Electrical and Electronics Engineering,

SRM Institute of Science and Technology, Kattankulathur, Tamilnadu, India.

Email: sattianandan.d@ktr.srmuniv.ac.in

\section{INTRODUCTION}

In recent years, as the consumption of power increased it is essential to increase the generation on demand. Nowadays the use of renewable energy such as solar, wind and tidal are effectively used for power generation. These renewable sources need not be at same place, they can be at different places based on energy availability. So, even the role of microgrid has become prominent. A microgrid is a small-scale power supply network that can generate, distribute and control power in a small community. Microgrid comprises of renewable power generating sources and storage devices that make it profoundly reliable and proficient. Proper integration between distributed energy resources, battery storage system and different loads delivers good quality of power to the consumers. An interesting aspect of the microgrid is its capability to work in grid-connected mode and islanded mode [1-4].

Based on the nature of signals, Microgrids are classified into AC and DC microgrids. With the ongoing research, DC microgrid proves to be more significant than AC microgrid. The concern of AC microgrid involves reactive power issues, power factor correction, frequency control, poor voltage regulation and presence of skin effect. DC microgrids are potentially more efficient, economical, more reliable, easy to 
store and control than AC microgrid. Current research on DC microgrids deals with system design, control modeling and stability of various converters and integration of DERs with the microgrid [5]. The operation of LVDC microgrid relies on the converter selection and control system design. In DC microgrid, DERs are integrated with converters to a common LVDC bus. By connecting DC-DC converters in parallel, effective current at the load can be doubled and if one module fails the other module compensates the output load [6, 7]. Integration of DERs with DC-DC converters to a common bus involves a lot of limitations such as improper load sharing, circulating currents and poor voltage regulation due to varying sources voltages, cable resistances and load changes.

The droop control technique eliminates the circulating currents of the parallel converters and improves the voltage regulation. Many droop control techniques have evolved from recent years and the most familiar control strategies are centralized (Master-Slave) and decentralized (Voltage Droop). In Mater Slave current method, a common bus for sharing current is used among converters to produce proficient bus voltage. The main constraint is that the whole system will get affected if there is a failure in the signal of the current bus [8]. Droop control design involves two controller loops, the first one is a voltage control loop which improves the voltage regulation and the second one is a current control loop which reduces the circulating currents in between the parallel converters [9-12]. The control loops using PI, PID and SMC have been designed to stabilize the performance of load current and output voltage. The PI control loops have been discussed in [13]. The major limitations of the droop control method are poor regulation of voltage and current sharing in between parallel converters because of droop activity. The significance of cable resistance is discussed in [14]. An alternative droop control method using fixed droop resistance using lag compensator is discussed in [9]. Since fixed droop resistance is only permitted to fixed load, an adaptive droop control method is discussed in [15-21].

The objective of this project is to solve the existing stability issue in the DC microgrid occurred by the source voltage variations and load changes. The most common techniques in DC microgrid for controlling converters are PI and PID controllers. These are the two control techniques that reduce the error by comparing the voltage reference with the output of the converter. Since the converters are non-linear $[22,23]$. A non-linear control technique has been implemented to solve the problem. Sliding mode controller is an effective tool used in designing robust controllers for non-linear dynamic systems operating under varying conditions. SMC has guaranteed linear stability and works for dynamic load and line uncertainties. [24-28], SM controller provides fast dynamic response, high robustness and good stability for large load variations [29-30]. Simulation results of performance characteristics of PI, PID and SMC are carried out to validate the research work.

\section{SYSTEM CONFIGURATTION}

This section deals with load sharing and current circulating issues of LVDC microgrid. A DC microgrid consisting of fixed input voltages $V_{i 1}$ and $V_{i 2}$ with dc-dc converters and common load is demonstrated in Figure 1. A DC-DC buck converter is taken as an interfacing converter between the source and the LVDC bus. The equivalent circuit of the parallel converters can be modeled as source voltage in series with the cable resistance connected to a common load as demonstrated in Figure 2. Voltage level plays a prominent role in deciding the system efficiency, cost and operation of DC microgrid. In this work, $48 \mathrm{~V}$ is taken as the LVDC bus voltage, Since the telecommunication industry, for the most part, utilizes $48 \mathrm{~V}$ and is the best choice for the LVDC transmission system. The case studies for parallel DC-DC converters are shown below in Table 1.

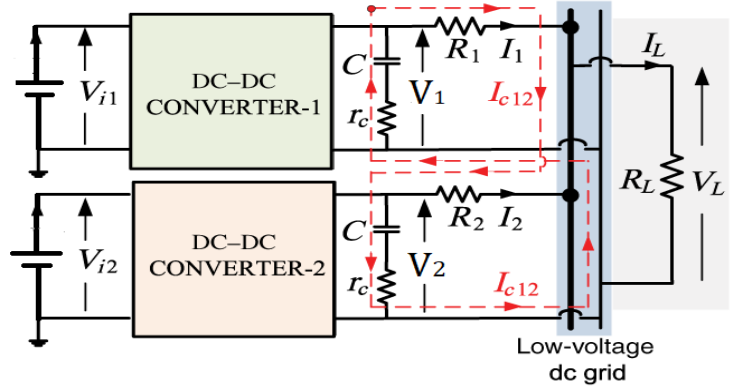

Figure 1. Parallel DC-DC converters

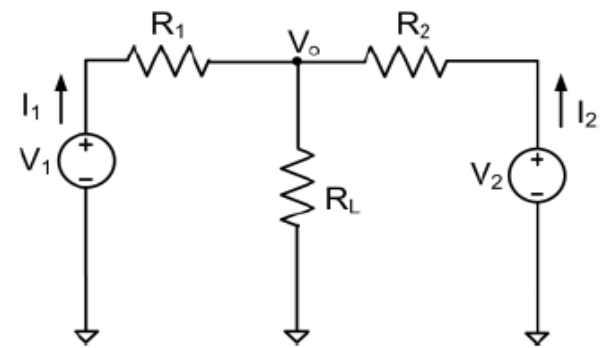

Figure 2. Equivalent Circuit 
Table 1. Case study of parallel DC-DC converters

\begin{tabular}{cccccc}
\hline Case & Cable resistances & Output voltages & Output currents & Output powers & Circulating currents \\
& $\mathrm{R}_{1}, \mathrm{R}_{2}$ & $\mathrm{~V}_{1}, \mathrm{~V}_{2}$ & $\mathrm{I}_{1}, \mathrm{I}_{2}$ & $\mathrm{P}_{2}$ & $\mathrm{I}_{\mathrm{C} 2}-\mathrm{I}_{\mathrm{C} 21}$ \\
\hline 1 & Equal & Equal & Equal & Equal & Zero \\
2 & Unequal & Equal & Unequal & Unequal & Not zero \\
3 & Equal & Unequal & Unequal & Unequal & Not zero \\
4 & Unequal & Unequal & Unequal & Unequal & Not zero \\
\hline
\end{tabular}

Applying Kirchhoff's Voltage Law in Figure 2.

$$
\begin{aligned}
& V_{1}-I_{1} R_{1}-\left(I_{1}+I_{2}\right) R_{L}=0 \\
& V_{2}-I_{2} R_{2}-\left(I_{1}+I_{2}\right) R_{L}=0
\end{aligned}
$$

$I_{1}$ and $I_{2}$ can be obtained by solving the equations (1) and (2).

$$
\begin{aligned}
& I_{1}=\frac{\left(R_{2}+R_{L}\right) V_{1}-R_{L} V_{2}}{R_{1} R_{2}+R_{1} R_{L}+R_{2} R_{L}} \\
& I_{2}=\frac{\left(R_{1}+R_{L}\right) V_{2}-R_{L} V_{1}}{R_{1} R_{2}+R_{1} R_{L}+R_{2} R_{L}}
\end{aligned}
$$

Circulating currents can be expressed as

$$
I_{C 12}=-I_{C 21}=\frac{V_{1}-V_{2}}{R_{1}+R_{2}}=\frac{I_{1} R_{1}-I_{2} R_{2}}{R_{1}+R_{2}}\left(\text { if } R_{1} \neq R_{2}\right)=\frac{I_{1}-I_{2}}{2}\left(\text { if } R_{1}=R_{2}\right)
$$

\section{PROPOSED CONTROL METHOD}

In this section, the detailed modeling and procedure for designing of sliding mode droop controller is being discussed. A droop resistance is incorporated within the controller to stabilize the system during variable source and load changes.

\subsection{System modelling}

The first step in designing SMC involves developing of desired control variables for the converter. The control signals given to the SMC are proportional to the control variables of the converter (i.e., voltage or current, etc.). Output voltage error is taken as the input control variable for the converter. Figure 3 demonstrates the general block diagram of SMC.

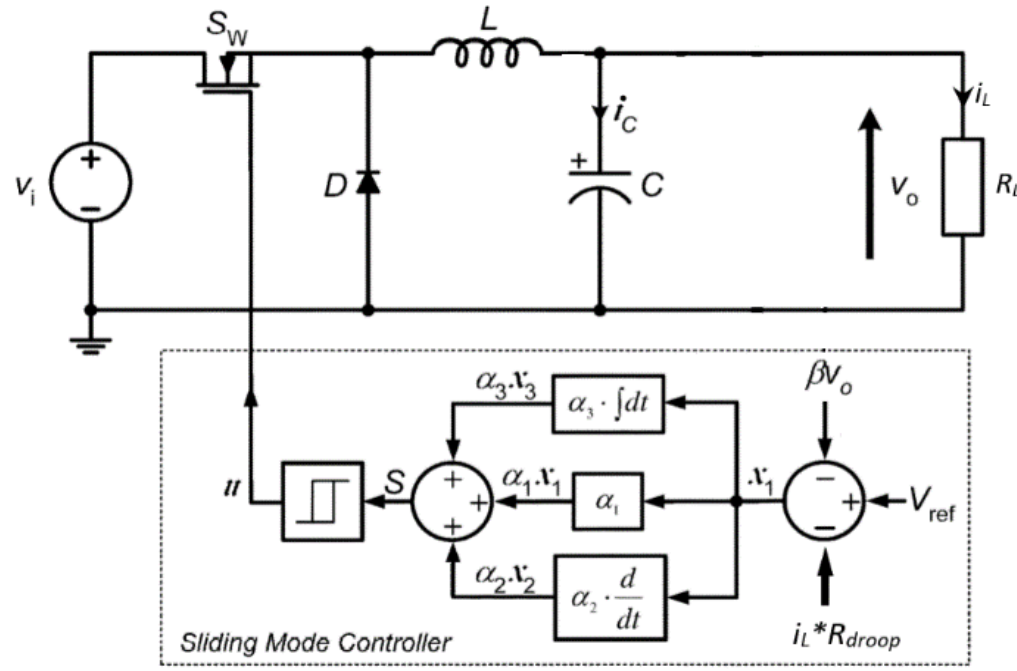

Figure 3. General block diagram of SMC buck converter

The control variable ' $x$ ' of the converter can be expressed as: 


$$
x=\left[\begin{array}{l}
x_{1} \\
x_{2} \\
x_{3}
\end{array}\right]=\left[\begin{array}{c}
V_{\text {ref }}-\beta \mathrm{V}_{0}-\mathrm{I}_{1} \mathrm{R}_{\text {droop }} \\
\frac{\mathrm{d}}{\mathrm{dt}}\left(\mathrm{V}_{\text {ref }}-\beta \mathrm{V}_{0}-\mathrm{I}_{\mathrm{I}} \mathrm{R}_{\text {droop }}\right) \\
\int\left(\mathrm{V}_{\text {ref }}-\beta \mathrm{V}_{\mathrm{o}}-\mathrm{I}_{1} \mathrm{R}_{\text {droop }}\right) \mathrm{dt}
\end{array}\right]
$$

Where, $x_{1}=$ Proportional voltage error

$x_{2}=$ Differential voltage error

$x_{3}=$ Integral voltage error

Where, $\beta$ - Feedback factor

$\mathrm{i}_{\mathrm{L}}, \mathrm{i}_{\mathrm{c}}-$ Load and Capacitive currents

$\mathrm{R}_{\text {droop }}$ - Droop Resistance

$\mathrm{V}_{\text {ref, }} \mathrm{V}_{\mathrm{i}}, \mathrm{V}_{\mathrm{o}}-$ Reference, Source and Output voltages

\subsection{Controller design}

Sliding mode controller design is derived from variable control matrix. The controller design calculations are given below.

$$
\begin{aligned}
\mathrm{S} & =\alpha_{1} x_{1}+\alpha_{2} x_{2}+\alpha_{3} x_{3} \\
& =\alpha_{1} x_{1}+\alpha_{2} \frac{d x_{1}}{d t}+\alpha_{3} \int x_{1} d t
\end{aligned}
$$

solving the equations from (6) and (7) we get

$$
\begin{aligned}
& \mathrm{V}_{\text {control }}=-\mathrm{K}_{\mathrm{p} 1} \mathrm{i}_{\mathrm{c}}+\mathrm{K}_{\mathrm{p} 2}\left(\mathrm{~V}_{\text {ref }}-\beta \mathrm{V}_{\mathrm{o}}-\mathrm{I}_{1} \text { Rdroop }\right)+\beta \mathrm{Vo}_{\mathrm{o}} \\
& \text { Vramp }=\beta \mathrm{Vo}_{\mathrm{o}} \\
& \text { Where, } \mathrm{Kp} 1=\beta \mathrm{L}\left(\frac{\alpha_{1}}{\alpha_{2}}-\frac{1}{\mathrm{R}_{\mathrm{L}} \mathrm{C}}\right) \\
& \mathrm{Kp} 2=\mathrm{LC} \frac{\alpha_{3}}{\alpha_{2}} \\
& \frac{\alpha_{1}}{\alpha_{2}}=\frac{10}{\mathrm{~T}_{\mathrm{S}}} \\
& \frac{\alpha_{3}}{\alpha_{2}}=\frac{25}{\delta^{2} \mathrm{~T}_{\mathrm{S}}^{2}}
\end{aligned}
$$

where $\alpha_{1}, \alpha_{2}, \alpha_{3}$ are sliding coefficients, $\delta$ is the damping constant, $\mathrm{T}_{\mathrm{s}}$ is the desired settling time. The overall control structure of SMC is demonstrated in Figure 4. The controller design parameters for SMC are mentioned in Table 2.

Table 2. Parameters of SMC

\begin{tabular}{ll}
\hline Parameters & Values \\
\hline Input Voltage $V_{\text {in }}$ & $100 \mathrm{~V}$ \\
Output Voltage $V_{o}$ & $48 \mathrm{~V}$ \\
Reference Voltage $V_{\text {ref }}$ & $48 \mathrm{~V}$ \\
Switching Frequency $f_{s}$ & $10 \mathrm{KHZ}$ \\
Inductance $L$ & $0.479 \mathrm{mH}$ \\
Capacitance $C$ & $271.25 \mu \mathrm{F}$ \\
Inductor Resistance $r_{L}$ & $0.002 \Omega$ \\
ESR of capacitor $R_{C}$ & $0.03 \Omega$ \\
Peak to peak inductor current & $10 \%$ \\
ripple percentage $2 \Delta i_{L}$ & \\
Ripple factor of peak output & $5 \%$ \\
voltage $\Delta V_{o}$ & \\
Droop Resistance $R_{\text {droop }}$ & $0.6 \Omega$ \\
Duty Cycle $D$ & 0.48 \\
$K_{P 1}$ & 1.6466 \\
$K_{P 2}$ & 2 \\
$\beta$ & 0.95 \\
Damping Constant $\delta$ & 0.5 \\
Settling Time $T_{s}$ & $2.546 \mathrm{~ms}$ \\
\hline
\end{tabular}

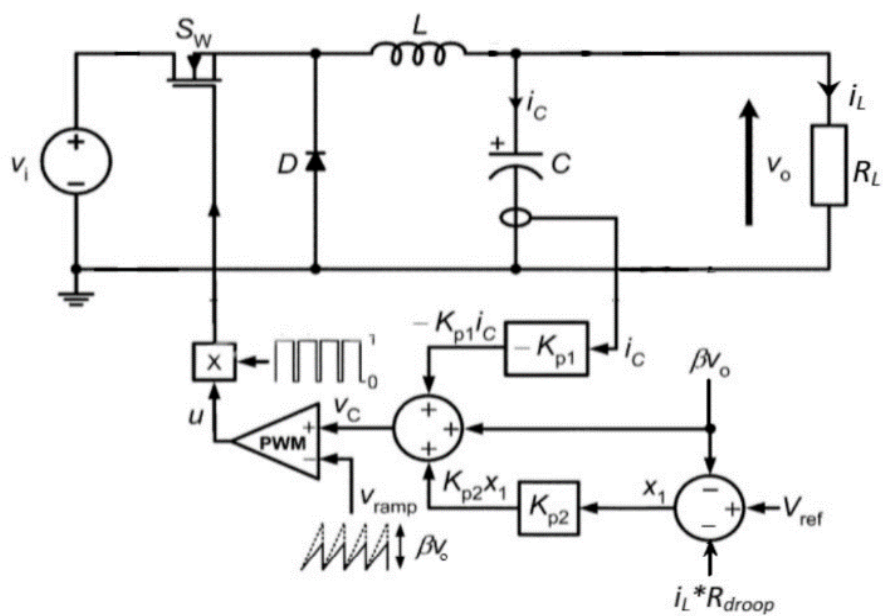

Figure 4. Control Structure of SMC buck converter 


\section{SIMULATION RESULTS}

Different droop control techniques were performed on two parallel buck converters using MATLAB/Simulink and the output results were recorded. To compare the performance of SMC with PI and PID controller's different converter parameters such as varying cable resistance, varying source voltage and load changes are considered at different intervals as mentioned in Table 3.

Table 3. Input voltage and load variations at different intervals

\begin{tabular}{|c|c|c|c|c|}
\hline Time $(\mathrm{sec}) \rightarrow$ & $0-1$ & $1-2$ & $2-3$ & $3-4$ \\
\hline Input Voltage of Converter-1 & $100 \mathrm{~V}$ & $100 \mathrm{~V}$ & $110 \mathrm{~V}$ & $100 \mathrm{~V}$ \\
\hline Input Voltage of Converter-2 & $100 \mathrm{~V}$ & $110 \mathrm{~V}$ & $100 \mathrm{~V}$ & $100 \mathrm{~V}$ \\
\hline Load Resistance $\left(\mathrm{R}_{\mathrm{L}}\right)$ & $11.95 \Omega$ & $15.36 \Omega$ & $11.95 \Omega$ & $15.36 \Omega$ \\
\hline
\end{tabular}

\subsection{PI controller with same cable resistance, different source voltage, and different load}

Figure 5 displays the load voltage and output currents waveform of PI controller at different loads $11.95 \Omega, 15.36 \Omega$ and varying source voltages $100 \mathrm{~V}$ and $110 \mathrm{~V}$. It is observed that the load voltage is almost equal for different loads with peak overshoots during load variations and output current is $3.893 \mathrm{~A}$ for 11.95 $\Omega$ and 3.048 A for $15.36 \Omega$. It is observed that the converters undergo large oscillations at varying conditions.

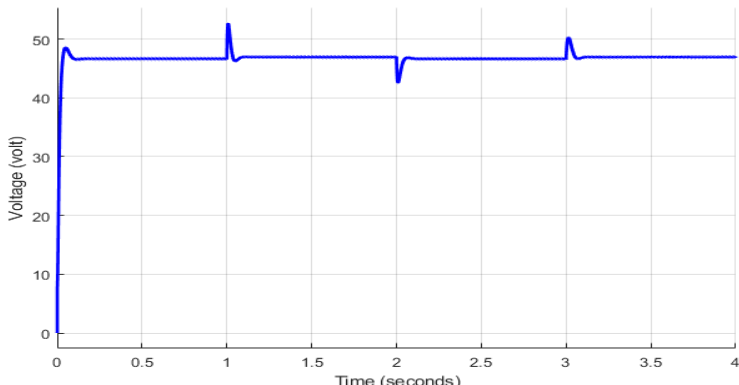

(a)

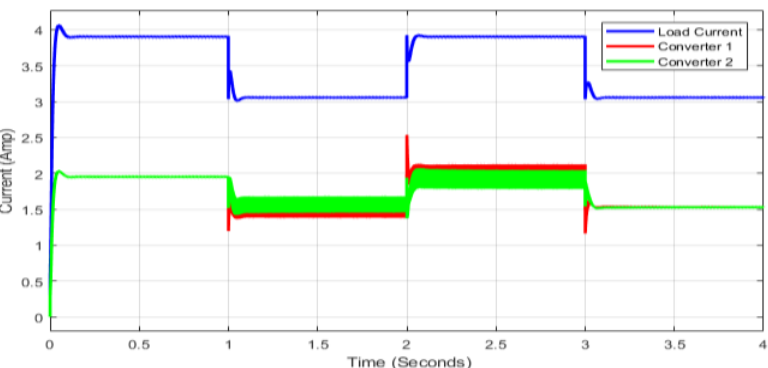

(b)

Figure 5. Simulation results for PI controller with same cable resistance

(a) Load voltage (b) output currents and load current of converters

\subsection{PID controller with same cable resistance, same source voltage and different load}

Figure 6 displays the load voltage and output currents waveform of PID controller at different loads $11.95 \Omega, 15.36 \Omega$ and equal source voltages $100 \mathrm{~V}$. It is observed that the load voltage is almost equal for different loads with little disturbances during load variations and output current is 3.909 A for $11.95 \Omega$ and 3.14 A for $15.36 \Omega$. PID Controllers only work for same cable resistances, same source voltages because the controller gain values are tuned for prefixed values and the system doesn't work for variable voltages and varying cable resistances.

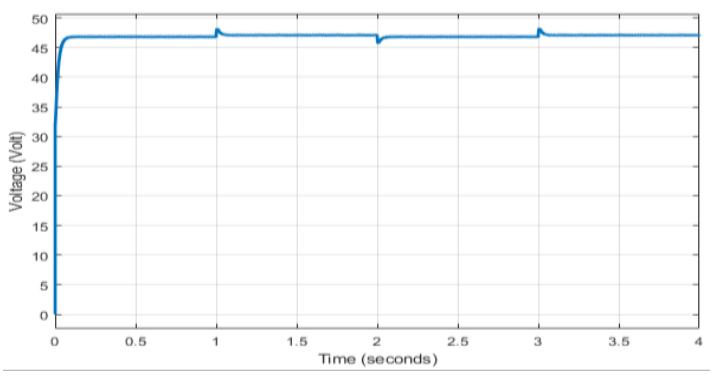

(a)

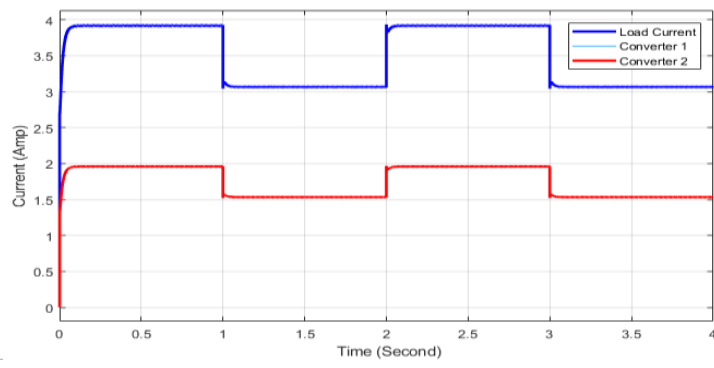

(b)

Figure 6. Simulation results for PID controller with same cable resistance

(a) Load voltage (b) output currents and load current of converters 


\subsection{SMC with same cable resistance, different source voltage and different load}

Figure 7 displays the load voltage and output currents waveform of SM controller at different loads $11.95 \Omega, 15.36 \Omega$ and varying source voltages $100 \mathrm{~V}$ and $110 \mathrm{~V}$. It is observed that the load voltage is equal for different loads with no disturbances during load variations and output current is $3.954 \mathrm{~A}$ for $11.95 \Omega$ and 3.118 A for $15.36 \Omega$.

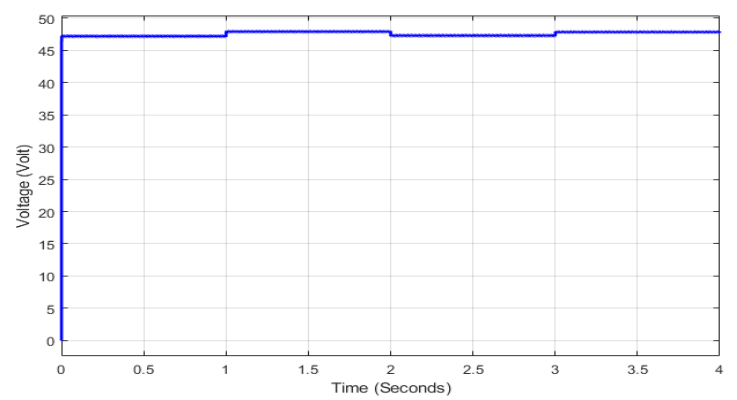

(a)

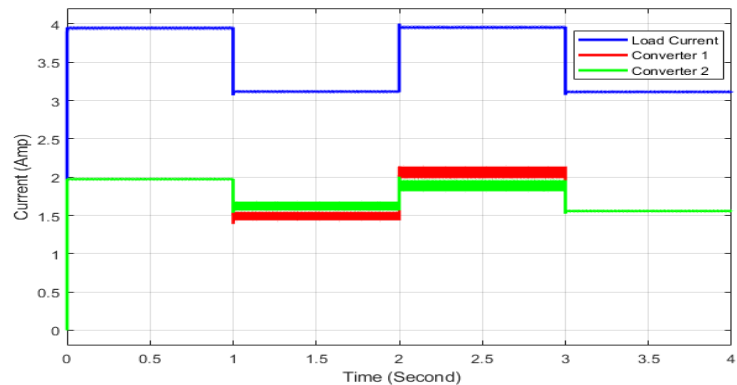

(b)

Figure 7. Simulation results for SM controller with same cable resistance

(a) Load voltage (b) output currents and load current of converters

\subsection{PI controller with different cable resistance, different source voltage and different load}

Figure 8 displays the load voltage and output currents waveform of PI controller at different loads $11.95 \Omega, 15.36 \Omega$ and varying source voltages $100 \mathrm{~V}$ and $110 \mathrm{~V}$. It is observed that the load voltage is almost equal for different loads with peak overshoots during load variations and output current is 3.889 A for 11.95 $\Omega$ and 3.045 A for $15.36 \Omega$. It is observed that the converters undergo large oscillations at varying conditions.

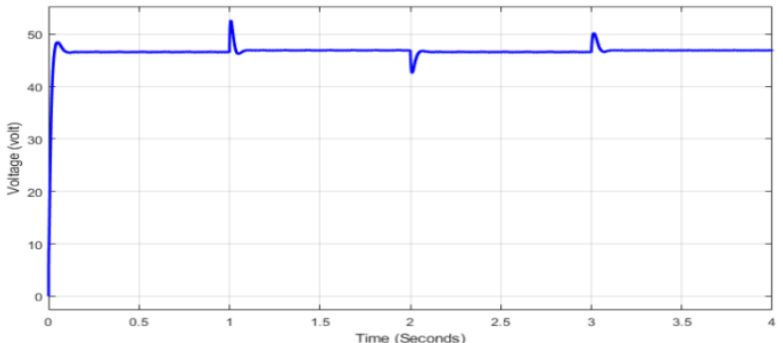

(a)

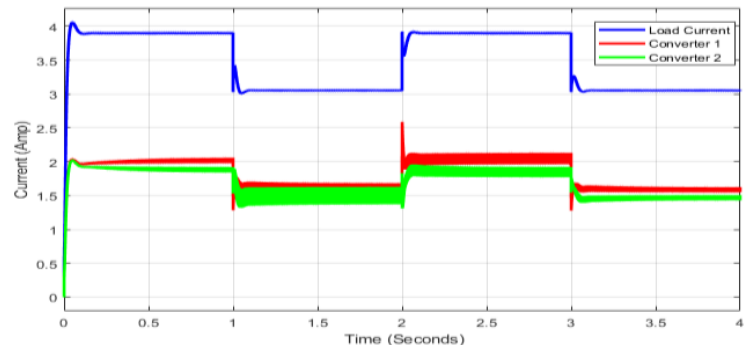

(b)

Figure 8. Simulation results for PI controller with different cable resistance

(a) Load voltage (b) output currents and load current of converters

\subsection{SMC with different cable resistance, different source voltage and different load}

Figure 9 displays the load voltage and output currents waveform of SM controller at different loads $11.95 \Omega, 15.36 \Omega$ and varying source voltages $100 \mathrm{~V}$ and $110 \mathrm{~V}$. It is observed that the load voltage is equal for different loads with no disturbances during load variations and output current is 3.952 A for $11.95 \Omega$ and 3.103 A for $15.36 \Omega$.

The results shown in Table 4, 5, 6, 7 it can be justified that the SMC gives better results for varying conditions and is more stable than PI and PID controllers. Droop control using PI controller results in peak overshoots and disturbances during varying source voltage and load changes and PID controller resolves the issue by adding a derivative term but the main disadvantage of PID is that it works only for same voltage and same cable resistance because the system parameters are autotuned in such a way that the system works only for fixed values. These disturbances in PI and PID results in poor voltage regulation, improper load sharing and circulating current issues. SMC offers better voltage regulation and minimizes the circulating currents. 


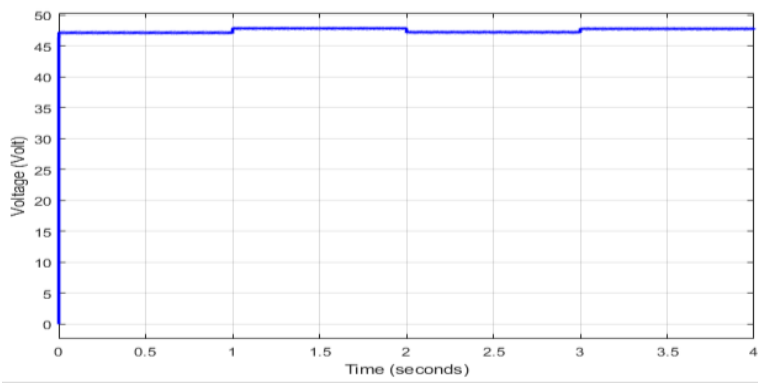

(a)

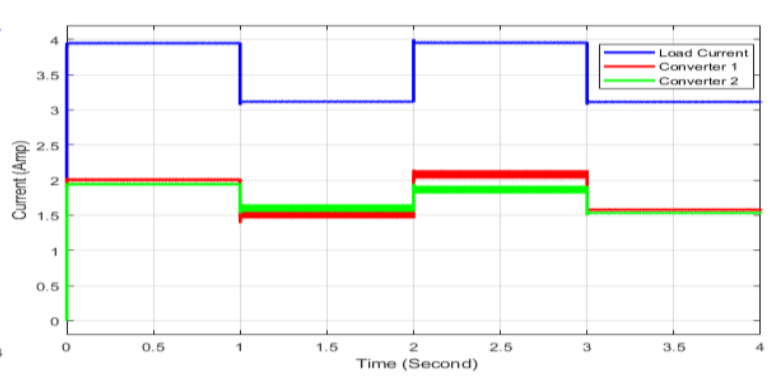

(b)

Figure 9. Simulation results for SM controller with different cable resistance

(a) Load voltage (b) output currents and load current of converters

Table 4. $\mathrm{R}_{1}=0.1 \Omega, \mathrm{R}_{2}=0.1 \Omega, \mathrm{R}_{\mathrm{L}}=11.95 \Omega, \mathrm{T}=$ $0-1 \mathrm{~s}$ and $2-3 \mathrm{~s}, \mathrm{P}=192 \mathrm{~W}$

\begin{tabular}{ccccccc}
\hline & $\mathrm{V}_{1}$ & $\mathrm{~V}_{2}$ & $\mathrm{~V}_{\mathrm{L}}$ & $\mathrm{I}_{1}$ & $\mathrm{I}_{2}$ & $\mathrm{I}_{\mathrm{L}}$ \\
\hline PI & 46.72 & 46.72 & 46.52 & 1.947 & 1.947 & 3.893 \\
PID & 46.71 & 46.71 & 46.50 & 1.954 & 1.954 & 3.909 \\
SMC & 47.44 & 47.44 & 47.25 & 1.977 & 1.977 & 3.954 \\
\hline
\end{tabular}

Table 6. R1=0.1 $\Omega, \mathrm{R} 2=0.15 \Omega, \mathrm{RL}=11.95 \Omega$,

\begin{tabular}{ccccccc}
\multicolumn{6}{c}{$\mathrm{T}=0-1 \mathrm{~s}$ and $2-3 \mathrm{~s}, \mathrm{P}=192 \mathrm{~W}$} \\
\hline & $\mathrm{V}_{1}$ & $\mathrm{~V}_{2}$ & $\mathrm{~V}_{\mathrm{L}}$ & $\mathrm{I}_{1}$ & $\mathrm{I}_{2}$ & $\mathrm{I}_{\mathrm{L}}$ \\
\hline PI & 46.68 & 46.76 & 46.48 & 2.004 & 1.885 & 3.889 \\
SMC & 47.43 & 47.52 & 47.23 & 2.012 & 1.94 & 3.952 \\
\hline
\end{tabular}

Table 5. R1 $=0.1 \Omega, \mathrm{R} 2=0.1 \Omega, \mathrm{RL}=15.36 \Omega, \mathrm{T}=1-2 \mathrm{~s}$ and $3-4 \mathrm{~s}, \mathrm{P}=150 \mathrm{~W}$

\begin{tabular}{ccccccc}
\hline & $\mathrm{V}_{1}$ & $\mathrm{~V}_{2}$ & $\mathrm{~V}_{\mathrm{L}}$ & $\mathrm{I}_{1}$ & $\mathrm{I}_{2}$ & $\mathrm{I}_{\mathrm{L}}$ \\
\hline PI & 46.96 & 46.96 & 46.81 & 1.524 & 1.524 & 3.048 \\
PID & 46.94 & 46.94 & 46.78 & 1.57 & 1.57 & 3.14 \\
SMC & 48.05 & 48.05 & 47.9 & 1.559 & 1.559 & 3.118 \\
\hline
\end{tabular}

Table 7. $\mathrm{R}_{1}=0.1 \Omega, \mathrm{R}_{2}=0.15 \Omega, \mathrm{R}_{\mathrm{L}}=15.36 \Omega, \mathrm{T}=1-2 \mathrm{~s}$ and $3-4 \mathrm{~s}, \mathrm{P}=150 \mathrm{~W}$

\begin{tabular}{ccccccc}
\hline & $\mathrm{V}_{1}$ & $\mathrm{~V}_{2}$ & $\mathrm{~V}_{\mathrm{L}}$ & $\mathrm{I}_{1}$ & $\mathrm{I}_{2}$ & $\mathrm{I}_{\mathrm{L}}$ \\
\hline PI & 46.93 & 46.99 & 46.77 & 1.585 & 1.46 & 3.045 \\
SMC & 47.82 & 47.89 & 47.66 & 1.566 & 1.537 & 3.103 \\
\hline
\end{tabular}

\section{CONCLUSION}

In this paper, different control techniques for controlling a low voltage microgrid were designed and simulated using MATLAB/Simulink. The test cases were recorded by varying different parameters and the output characteristics were compared. The PI and PID control methods offer a simpler control system than the SMC method and also offer faster operation but cause peak overshoots and increase in settling time during the start and cause slight disturbances in the output voltage and load current during variations in source voltage and load. The proposed SMC droop control method offers a better stable response by eliminating the peak overshoots and oscillations without affecting the system.

\section{REFERENCES}

[1] Huang Jiayi, Jiang Chuanwen and Xu Rong, "A review on distributed energy resources and Microgrid." Renewable and Sustainable Energy Reviews, vol. 12, no.9, pp. 2472-2483, Dec. 2008.

[2] Iván Patraon, Emilio Figueres, Gabriel Garcerá and Raúl González-Medina, "Microgrid architectures for low voltage distributed generation." Renewable and Sustainable Energy Reviews, vol. 43, no. 9, pp. 415-424, 2015.

[3] M. Lexuen, S. Qobad, D. Fulwani, F, Fulwani, and J. Josep, "Review on control of dc-microgrid", IEEE Emerging, Selec., vol. 5, no. 3. pp. 928- 948, Sept. 2017.

[4] Dong Chen and Lie Xu, "AC and DC Microgrid with Distributed Energy Resources," Technologies and Applications for Smart Charging of Electric and Plug-in Hybrid Vehicles,2018

[5] Liyue Zhang, Weiliang Zhang, Fanzheng Zeng and Xiongzhen Yang, "A Review of Control Strategies in DC Microgrid.”IOP Conference Journal of Physics, vol. 1087, no. 4, 2018.

[6] Rodrigo A F. Ferreira1, Henrique AC. Braga1, Andre A Ferreira1 and Pedro G. Barbosa1, "Analysis of Voltage Droop Control Method for dc Microgrids with Simulink: Modelling and Simulation." 10th IEEE/IAS International Conference on Industry Applications, Nov. 2012.

[7] E.G Shehata, Jean Thomas, R.M. Mostafa and M.A. Ghalib, "An Improved Droop Control for a Low Voltage DC Microgrid Operation." Twentieth International Middle East Power Systems Conference (MEPCON), Dec. 2018.

[8] Girish G. Talapur, H. M. Suryawanshi, Amardeep B. Shitole, Rohit R. Deshmukh, and M. S. Ballal, "MasterSlave Control based Reliable Micro-Grid with Back-to-Back Voltage Source Converter as Master DG." $43^{r d}$ annual conference of IEEE Industrial Electronics Socity (IECON), Nov. 2017. 
[9] Daniel Zammit, Cyril Spiteri Staines, Maurice Apap and Alexander Micallef, "Alternative Droop Control Method using a Modified Lag Compensator for Paralleled Converters in DC Microgrids." 6th International Conference on Control, Decision and Information Technologies (CoDIT'19), April 2019.

[10] Sikander Ali, Tang Shengxue, Zhang Jianyu, Ahmad Ali and Arshad Nawaz "An Implementation of Parallel Buck Converters for Common Load Sharing in DC Microgrid”, www.mdpi.com/journal/information ,vol. 10, no. $91,2019$.

[11] D. Zammit, C. S. Staines, M. Apap and A. Micallef, "overview of buck and boost converters modelling and control for standalone de microgrid operation" Offshore Energy \& Storage Symposium, OSES, July 2016.

[12] Vinu Thomas, Kumaravel S. and Ashok S, "Control of Parallel DC-DC Converters in a DC Microgrid Using Virtual Output Impedance Method", $2^{\text {nd }}$ International Conference on Advances in Electrical, Electronics, Information, Communication and Bio Informatics (AEEICB), Feb. 2016.

[13] D. Zammit, C. S. Staines, M. Apap and A. Micallef, "Paralleling of buck converters for DC microgrid operation," International Conference on Control, Decision and Information Technologies, St. Julian's, 2016.

[14] Sijo Augustine, Mahesh K. Mishra and N. Lakshminarasamma, "Adaptive Droop Control Strategy for Load Sharing and Circulating Current Minimization in Low-Voltage Standalone DC Microgrid" IEEE Transactions on sustainable energy, vol. 6, no.4, Jan. 2015.

[15] Vahidreza Nasirian, Ali Davoudi, Frank L. Lewis and Josep M. Guerrero, "Distributed Adaptive Droop Control for DC Distribution Systems.” IEEE Transactions on energy conversion, vol. 29, no. 4, Dec. 2014.

[16] Amir Khorsandi, Mojtaba Ashourloo1 Hossein Mokhtari and Reza Iravani, "Automatic droop control for a low voltage DC microgrid.” IET Generation, Transmission and Distribution. vol. 10, no.1, pp. 41 - 47, Jan. 2016.

[17] Ganesh R, Gayadhar Panda and Rangababu peesapati, "Hardware-in-loop Implementation of an Adaptive Droop Control Strategy for Effective Load Sharing in DC Microgrid." IEEE 6th International Conference on Power Systems (ICPS), March 2016.

[18] Avisha Tah and Debapriya Das, "An Enhanced Droop Control Method for Accurate Load Sharing and Voltage Improvement of Isolated and Interconnected DC Microgrids." IEEE Transactions on sustainable energy, vol. 7, no. 3, pp. 1194 - 1204, July 2016.

[19] Panbao Wang, Xiaonan Lu, Xu Yang, Wei Wang and Dianguo Xu, “An Improved Distributed Secondary Control Method for DC Microgrids with Enhanced Dynamic Current Sharing Performance." IEEE Transactions on power electronics, vol. 31, no. 9, pp. 6658 - 6673 Sept. 2016.

[20] Guangyuan Liu, Tommaso Caldognetto, Paolo Mattavelli and Paolo Magnone, "Power-Based Droop Control in DC Microgrids Enabling Seamless Disconnection from Upstream Grids." IEEE Transactions on power electronics, vol. 34, no. 3, pp. 2039 - 2051, March 2019.

[21] Jafar Mohammad and Firouz Badrkhani Ajaei, "Improved Mode-Adaptive Droop Control Strategy for the DC Microgrid." IEEE Access, vol. 7, no. 6, pp. 86421 - 86435, June 2019.

[22] Fang Chen, Rolando Burgos, Dushan Boroyevich, Juan C. Vasquez, and Josep M. Guerrero, "Investigation of Nonlinear Droop Control in DC Power Distribution Systems: Load Sharing, Voltage Regulation, Efficiency, and Stability.” IEEE Transactions on Power Electronics, vol. 34, no. 10, pp. 9404 - 9421, Oct. 2019.

[23] P.M. Meshram and Rohit G. Konojia, "Tuning of PID Controller using Ziegler-Nichols Method for Speed Control of DC Motor." IEEE- International Conference on Advances in Engineering, Science and Management (ICAESM -2012), March 2012.

[24] Siew-Chong Tan, Y. M. Lai and Chi K. Tse, "A Unified Approach to the Design of PWM-Based Sliding-Mode Voltage Controllers for Basic DC-DC Converters in Continuous Conduction Mode." IEEE Transactions on Circuits and Systems -I: Regular Papers, vol. 53, no. 8, pp. 1816 - 1827, Aug. 2006.

[25] Syed Ali Akbar Hussainy, Revant Ganguli Tandon and Saurav Kumar, "PWM Based Sliding Mode Control of DC-DC Converters." International Conference on Advances in Power Conversion and Energy Technologies (APCET), Aug. 2012.

[26] Leonardy Setyawan, Wang Peng and Xiao Jianfang, "Implementation of Sliding Mode Control in DC Microgrids." 9th IEEE Conference on Industrial Electronics and Applications, June 2014.

[27] Kruti. R. Joshi and Hardik V. Kannad, "Design of Sliding Mode Control for BUCK Converter." International Journal of Advanced Research in Electrical, Electronics and Instrumentation Engineering, vol. 4, no. 5, 2015.

[28] A. Karthikayeni, S. Ramaprasath and P. Rameshbabu, "Modeling and Simulation of PWM Based Sliding Mode Voltage Controller for Boost Converter in Continuous Conduction Mode." International Conference on Circuit, Power and Computing Technologies [ICCPCT], March 2015.

[29] M. Rashad, U. Raoof and B. Ashfq, "Proportional Load Sharing and Stability of DC Microgrid with Distributed Architecture Using SM Controller”, Math., In Eng., pp. 1-16, Jan 2018.

[30] Sandeep Tyagi and Garima Verma, "Simulation and Analysis of DC-DC Boost Converter Using Sliding Mode Controller under Variable Conditions." in IOSR Journal of Electrical and Electronics Engineering (IOSR-JEEE), vol. 13, no. 1, pp. 33-41, Jan. 2018. 